\title{
Raúl Prebisch y la vida cultural tucumana*
}

\author{
Darlan Praxedes
}

Universidade de São Paulo

S ecretario Ejecutivo de la Comisión Económica para América Latina y el Caribe (CEPAL) de las Naciones Unidas, entre 1949 y 1962, fundador y primer director del Instituto Latinoamericano y del Caribe de Planificación Económica y Social (ILPES) y de la Conferencia de las Naciones Unidas sobre Comercio y Desarrollo (UNCTAD), Raúl Prebisch (1901-1986) suele ser considerado en los medios intelectuales y políticos el creador de instituciones, fundador -junto con el brasileño Celso Furtado- del "estructuralismo latinoamericano", "padre del desarrollo" e ideólogo del "desarrollismo" en esa región. ${ }^{1}$

Sin embargo, su imagen en la Argentina es muy diferente y revela otro Prebisch, considerado por la militancia nacionalista y peronista, hasta el día de hoy, como un "vendepatria" por su participación en los gobiernos de la "década infame" (1930-1943) y la elaboración del plan económico de la "Revolución Libertadora" de 1955, el "Plan Prebisch".

Al referirse a esta dicotomía David Pollock hace la pregunta correcta, pero, al igual que otros admiradores e intérpretes de las ideas de Prebisch, no encuentra cómo enmarcar el problema en términos satisfactorios: “¿Cuál fue el ‘verdadero’ Raúl Prebisch?”. ${ }^{2}$ En otras pala-

\footnotetext{
*Agradezco las sugerencias de Luiz Jackson, Alejandro Blanco, Jimena Caravaca, Sergio Miceli, Lidiane Rodrigues y a los evaluadores anónimos de Prismas. Agradezco muy especialmente a Lucas D'Avenia por su generosidad al traducir este texto.

${ }^{1}$ Véase la introducción de Ricardo Bielschowsky para el libro Cinquenta anos de pensamento na Cepal, en Ricardo Bielschowsky (comp.), Río de Janeiro, Record, 2000, pp. 15-68. Del mismo autor, Pensamento econômico brasileiro: o ciclo ideológico do desenvolvimentismo, Río de Janeiro, Contraponto, 1988. Véanse también la síntesis de Cristóbal Kay, "Teorías latinoamericanas del desarrollo", Nueva Sociedad, n 113, 1991, pp. 101-113, y Octavio Rodriguez, Teoria do subdesenvolvimento da Cepal, Río de Janeiro, Forense Universitária, 1981.

${ }^{2}$ La cita completa es la siguiente: "[...] simultáneamente la vida de Prebisch proyecta una doble imagen, casi la de una personalidad escindida. Aparece primero el Prebisch internacional de la CEPAL, la UNCTAD, y, sobre todo, la prestigiosa personalidad de la ONU: fundador del estructuralismo, innovador y artífice de instituciones, el que propuso la integración regional de América Latina y el incansable luchador por la justicia en las relaciones globales y regionales. [...]. El otro Prebisch -durante los años en que se desempeñó en la función pública en la Argentina y antes de su expulsión del Banco Central en octubre de 1943- es irreconocible. En ese período la imagen de Raúl fue otra. Era todo menos el reformista de los años posteriores y se lo asociaba, en cambio, con la oligarquía argentina y la Restauración Conservadora de los años 1930-1943, período conocido como la 'década infame'. Trascendió como el beneficiario del golpe de Estado del 6 de septiembre de 1930, dirigido por el General José Félix Uriburu, quien lo designó subsecretario de Hacienda a la edad de 29 años [...]. La prestigiosa figura pública de Prebisch en la onU a partir de 1949 parecía muy diferente en su estilo personal a aquella de los años previos a 1943. [...]. ¿Cuál era el
} 
bras, ¿es Prebisch el "caudillo intelectual y el profeta armado" "3 de la CEPAL o es el cerebro de la política económica de la oligarquía argentina y de la restauración conservadora? La pregunta palpitante de Pollock difícilmente podría ser resuelta por alguien tan cercano a "Don Raúl". Tampoco sería respondida con determinación por los intérpretes y los seguidores de las ideas de Prebisch, que se esfuerzan -voluntariamente o no- por librarlo de la mala fama en su país de origen o simplemente prefieren ignorar las contradicciones de su carrera, creyendo así disminuir la importancia de la controversia y ponerle fin.

La solución de este rompecabezas no se logró completamente en los intentos por descubrir en el controvertido asesor del Ministerio de Finanzas y gerente del Banco Central al hereje de las Naciones Unidas, respetado y admirado por todos. Como lo que se estableció en el imaginario latinoamericano es la figura del maestro cepalino, este tipo de análisis interpreta el pasado de acuerdo con el futuro y selecciona arbitrariamente lo que prefigura al hombre de 1950 en el de 1930. Así, al establecer apresuradamente las continuidades entre uno y otro, ${ }^{4}$ este enfoque ignora las contradicciones de su vida y de su producción intelectual y proyecta a un hombre ficticio, es decir, siempre coherente, comprometido con la distribución del ingreso y la justicia en las relaciones globales y regionales. Pero las cosas no han sucedido así y la "doble imagen"5 de Prebisch sigue esperando una solución más satisfactoria.

Este artículo contribuye a esta discusión desde otro punto de partida dando un paso atrás en el análisis de la trayectoria de Prebisch y examinando las condiciones institucionales y culturales concretas que explican su aparición en la rica Argentina de entre siglos, así como el origen en las filas de la oligarquía provincial y su posterior activación en el contexto de la "década infame" y la defensa de los intereses agroexportadores. Estos datos no pueden ser abstraídos si el objetivo es entender la desventura de Prebisch en un país cuya historia se caracteriza por profundas divisiones sociales siempre actualizadas entre oligarquías y masas, que se intensificaron en la década de 1930 con la crisis económica y la polarización extrema del ambiente político.

Por lo tanto, se trata de tomar en serio dos problemas aún sin respuesta en la literatura: 1) ¿cómo explicar que uno de los intelectuales más reconocidos del siglo Xx -en América Latina y en el mundo- haya nacido en un país subdesarrollado y, aun más increíble, en una provincia lejana y supuestamente empobrecida del interior?; 2) ¿cómo explicar que un joven de esta provincia -que estudió ciencias económicas, una carrera nueva y sin prestigio- lograra convertirse en el hombre fuerte de la política económica argentina de 1930 ?

Estas cuestiones no se resolverían mediante la disyuntiva entre los dos Prebisch, el escudero fiel de la oligarquía y el creador del estructuralismo, ${ }^{6}$ ni mediante explicaciones coyuntu-

\footnotetext{
‘verdadero' Raúl Prebisch?”. David Pollock, “Raúl Prebisch: la esencia del líder”, en Edgard Dosman (comp.), Raúl Prebisch: el poder, los principios, y la ética del desarrollo, Buenos Aires, BID-INTAL, 2006, pp. 11-22.

${ }^{3}$ Joseph Hodara, Prebisch y la Cepal: substancia, trayectoria y contexto institucional, México, El Colegio de México, 1987.

${ }^{4}$ Vale la pena hacer justicia a la contribución de Jimena Caravaca y Ximena Espeche, "América Latina como problema y como solución: Robert Triffin, Daniel Cosío Villegas, Víctor Urquidi y Raúl Prebisch antes del Manifiesto Latinoamericano (1944-1946)", Desarrollo Económico, vol. 55, n 217, 2016, pp. 211-235; y también Carlos Mallorquín, "La vuelta alrededor del mundo de Raúl Prebisch antes de 1949", 2012, disponible en <http://www.centrocelsofurtado.org.br/interna.php?ID_M=847>. Ambos textos se basan en investigaciones rigurosas y son cautelosos a la hora de establecer relaciones entre los dos Prebisch.

${ }^{5}$ Pollock, "Raúl Prebisch: la esencia del líder".

${ }^{6}$ Cabe señalar que el proceso de "latinoamericanización" de Prebisch, su rápida conversión en liderazgo regional, se debió al contexto de la posguerra y a los incentivos para la renovación de las ciencias sociales en la región. Estos
} 
rales como la crisis de 1929 y el descrédito del liberalismo económico en el mundo y en la Argentina. Como intento demostrar en este artículo, las respuestas a las dos preguntas planteadas se encuentran respectivamente en la formación cultural que adquirió Prebisch en la vibrante y cosmopolita provincia de Tucumán, donde nació y vivió hasta los 17 años, y en el carácter patricio de su origen social (los Uriburu), que lo insertó en las redes del poder años más tarde.

La primera parte del artículo reconstruye el origen social de Prebisch subrayando los linajes patricios de este origen y su lógica de reproducción social y política en el norte de la Argentina. La segunda parte destaca la proyección que la familia Prebisch adquirió en el contexto de la vida cultural y política del norte de la Argentina y en Buenos Aires. La tercera y última parte detalla los procesos históricos, económicos y culturales que convirtieron a Tucumán en un moderno centro de producción e irradiación de cultura en las últimas décadas del siglo XIX y principios del XX.

\section{Origen social}

Los Prebisch son descendientes en la Argentina de la alianza matrimonial entre Albin Prebisch y Rosa Linares Uriburu. Alemán, natural de Colmintz, Sajonia, ${ }^{7}$ Albin (1862-1934) era hijo de Gottfried Ernest Prebisch y Amalia Jaeguer, una familia de pequeños agricultores. Trabajó en el servicio de correo entre las provincias del norte argentino (Salta, Tucumán y Jujuy) y Buenos Aires, fue contador del Banco de Londres, y, después de casarse con Rosa Linares Uriburu en 1888 y radicarse en Tucumán, fundó la "Imprenta Albin Prebisch", que se destacó en la vida cultural tucumana de las primeras décadas del siglo Xx. Asumió la cátedra de inglés en el Colegio Nacional de Tucumán, fue designado vicecónsul de los Países Bajos, figuró entre los fundadores y directores del Banco Comercial de Tucumán, participó de la fundación del Club Alemán y se integró al Club de Esperanto. ${ }^{8}$

temas, que escapan al alcance de este artículo, son tratados con claridad en el texto de Caravaca y Espeche, "América Latina como problema y como solución". Para una perspectiva comparativa del proceso de renovación y transnacionalización de las ciencias sociales en América Latina véase Alejandro Blanco, "As ciencias sociais no Cone Sul e a gênese de uma elite intelectual (1940-1964)", Tempo Social, vol. 19, n 1, 2007, pp. 89-114. Véase también Alejandro Blanco y Antonio Brasil Jr., "A circulação internacional de Florestan Fernandes", en Sociologia \& Antropologia, Río de Janeiro, vol. 8, n 1, 2018, pp. 69-107.

${ }^{7}$ El caso de Albin se sitúa en medio de las olas de emigración motivadas por conflictos políticos. Su llegada a mediados de la década de 1870 coincide con el período de mayor flujo migratorio de alemanes a la Argentina, relacionada probablemente con la Guerra Franco-Prusiana. En 1873 ingresaron al país 793 alemanes y entre 1871 y 1875 la media fue de 293, lo que refuerza la hipótesis de que la mayor proporción de emigrantes alemanes en esos años se explica por los conflictos internos generados en el proceso de unificación territorial y formación del Estado nacional alemán. Sin embargo, debe registrarse que la contribución alemana al stock poblacional que desembarca en la Argentina entre fines del siglo XIX y comienzo del siglo XX es minoritaria cuando se compara con los aportes masivos de italianos y españoles y, en menor medida, franceses. A diferencia de los italianos y los españoles, de comportamiento ascético y expectativas de ascenso social más dilatadas por la baja rentabilidad relativa de sus tareas manuales, los alemanes elegían actividades económicas inmediatamente rentables y, por eso, eran más afectos a las actividades comerciales para las cuales contaban con considerables ventajas. Véase Hernán Otero, Historia de los franceses en la Argentina, Buenos Aires, Biblos, 2012. Véase también Fernando Devoto, Historia de la inmigración en la Argentina, Buenos Aires, Sudamericana, 2009.

${ }^{8}$ Albin, el padre, integra la categoría de inmigrantes innovadores y modernizadores que abandonaron una estructura social demasiado rígida para insertarse en espacios que les daban mayor oportunidad a sus capacidades y les permi- 
No obstante su carencia de recursos (materiales y simbólicos) y la estructura social rígida de las comunidades patricias norteñas, se casó con una descendiente de estirpe aristocrática del norte argentino (los Uriburu y los Sancetenea) de lo que resultó una alianza con las élites del interior que le dio acceso a la alta sociedad criolla.

Hija de Lucía Uriburu Arias y de Segundo Linares Sancetenea, Rosa Linares Uriburu era heredera de dos de los más antiguos linajes argentinos. Lucía era nieta de José de Uriburu y Bastarrechea, español, natural de San Miguel de Mendata, que emigró hacia Argentina a fines del siglo XVIII para asumir en Salta un alto cargo en las Reales Aduanas del Alto Perú y que, al dedicarse al comercio agrícola y ganadero, se volvió uno de los hombres más ricos de la Argentina de su tiempo. Se casó con Manuela de Hoyos y Aguirre, emparentada por el tronco materno con Francisco Aguirre, conquistador del Perú, Chile y Tucumán y fundador de Santiago del Estero, lo que le permitió penetrar en los círculos oligárquicos locales. ${ }^{9}$

En lo que respecta a los Sancetenea, el abuelo materno de Raúl era nieto de José Calixto de Sancetenea, español oriundo de Fuenterrabía, que emigró a la Argentina en los años 1790 para servir al Virreinato del Río de la Plata como ayudante mayor y subdelegado de Rentas del Pueblo de la Rinconada (hoy ciudad de Jujuy), responsable del combate al contrabando y al fraude contra la Real Hacienda. Actuó incluso como subdelegado del Partido de la Puna y regidor del Cabildo de Salta. ${ }^{10}$

Los Uriburu y los Sancetenea, patriarcas de esos linajes, se manejaron hábilmente en medio de las luchas de independencia que, exitosas en 1816, convulsionaron a la colonia, dividida entre las fuerzas "realistas", partidarias del régimen colonial y organizadas bajo el comando de las Provincias Unidas del Río de la Plata, y los "independentistas", comandados por la Primera Junta de Gobierno de Buenos Aires. Alineados a fuerza de convicción e interés a los "españolistas" (tal vez el peso del interés haya sido más fuerte que la propia convicción), se movieron entre los bandos en lucha a medida que los acontecimientos se inclinaban a la derrota de los "realistas".

Sancetenea era conocido por los aliados de Martín de Güemes, general y líder independentista de Salta, como "un realista hasta los huesos" y en 1810, con la destitución del Virrey Baltasar Hidalgo de Cisneros y la sustitución de autoridades que impuso la Revolución de Mayo, se proclamó como uno de los "patriotas americanos". Derrotadas las fuerzas leales a Lima y destituidos los regidores del Cabildo de Salta, Sancetenea prestó juramento al nuevo gobierno y Manuel Belgrano, jefe del Ejército del Norte y del Cabildo de Salta, afirmó que “[...] el regidor 'patriota' Sancetenea no era tan 'realista hasta los huesos' como pareció serlo el regidor José de Uriburu, a quien, sin embargo, la Junta revolucionaria de Buenos Aires [...] había declarado nada menos que 'benemérito de la Patria". ${ }^{11}$

\footnotetext{
tían valorar y transmitir un conjunto de saberes previos en una sociedad nueva, en que tales saberes tenían enorme valor en razón de su escasez. Es por esa razón que, mientras los nativos tendieron a concentrarse en actividades tradicionales, los inmigrantes hicieron suyas las nuevas ocupaciones del sector secundario y terciario, adecuadas a sus habilidades y vocaciones. Cf. Otero, Historia de los franceses en la Argentina. Los datos sobre los niveles de alfabetización entre nativos e inmigrantes muestran que los alemanes tenían tasas más altas que los nativos y otros grupos de inmigrantes. Véase Roy Hora, Historia económica de la Argentina en el siglo XIX, Buenos Aires, Siglo XXI, 2010. ${ }^{9}$ Véase Fermín V. Arenas Luque, Genealogía de los Uriburu, Buenos Aires, Sociedad Impresora Americana, 1943.

${ }^{10}$ Carlos Ibarguren Aguirre, "Los antepasados: genealogía de sus respectivos linajes", 1983, disponible en <https:// issuu.com/alfonsobeccarvarela/docs/tomo_viii>.

${ }^{11}$ Ibid., p. 188.
} 
Así, los Uriburu se posicionaron con éxito en la vida política y económica argentina. Sus descendientes contrajeron matrimonio en los círculos de la alta sociedad local, lo que actuó como principio estructurante en la toma de decisiones y el accionar posterior, contribuyendo a extender su red familiar y su influencia a nivel regional y transregional. ${ }^{12}$ De los diez hijos de José de Uriburu, todos se casaron con los herederos de linajes tradicionales (Arias Cornejo, Cornejo Ceballos, Linares y Arenales) que traían aparejados un entramado de relaciones sociales, vinculaciones políticas y posesión de tierras. Se establecieron en la actividad mercantil próspera del norte argentino (en vínculo con redes mercantiles interregionales y tráfico de mulas con el Alto Perú) y participaron en las disputas internas entre los grupos dirigentes, convirtiéndose en actores políticos relevantes en las esferas local y nacional, particularmente los miembros de la segunda y la tercera generación. ${ }^{13}$

Los Sancetenea, cuyos negocios se arraigaban en la actividad minera boliviana, no gozaron de la misma suerte que los Uriburu para adaptarse a las contingencias políticas derivadas de la independencia, que abrió disputas fronterizas con Bolivia y Chile y creó obstáculos para la continuación de relaciones comerciales hasta entonces fluidas. Con el desplazamiento del eje económico y político de las provincias del norte hacia Buenos Aires, los intereses comerciales de los Sancetenea se vieron afectados y sus miembros se dispersaron al fijar residencia en Bolivia y la Argentina. Incluso sin constituir una identidad familiar sólida como los Uriburu, reforzaron sus vínculos con las élites nativas al promover alianzas matrimoniales con otras distinguidas familias locales (Linares, Cornejo, Patrón, Güemes y Uriburu), lo que les permitió un mayor acceso a los espacios políticos, como muestra la trayectoria de Segundo Linares (1837-1910).

\section{Los Prebisch y los temas culturales}

El abuelo de Raúl, Segundo, se formó como abogado, fue senador nacional entre 1875 y 1884, ministro en dos oportunidades en Salta y, por motivos políticos, se radicó en Jujuy en 1886. Allí fundó el periódico El Norte y llegó a ser el presidente local de la recién creada Unión Cívica.

Además de sus actividades políticas, fue profesor de latín y de literatura en el Colegio Nacional de Jujuy y, según Raúl Prebisch, poseía la mejor biblioteca de la región de Salta y Jujuy: "Siempre recuerdo la biblioteca de mi abuelo. Era un enorme salón. Siempre estaba al día. ¡Una biblioteca! La recuerdo como una cosa magnífica”. ${ }^{14}$ De acuerdo con Raúl, se debe a su abuelo la inclinación intelectual de los Prebisch: "Todos nosotros hemos tenido una propensión intelectual que, seguramente, viene del abuelo. [...] Mi abuelo era un gran lector, cosa meritoria en una provincia tan distante como aquella". ${ }^{15}$

\footnotetext{
${ }^{12}$ Véase María Fernanda Justiniano, Entramados del poder: Salta y la nación en el siglo XIX, Bernal, Universidad Nacional de Quilmes, 2010.

${ }^{13}$ La segunda generación de los Uriburu, hijos de José de Uriburu y tíos abuelos de Raúl, se destacaron en carreras militares. Fue con la tercera y la cuarta generación que el clan se extendería en diversos sectores de la vida política y administrativa argentina y alcanzaría su cumbre en la presidencia del país por dos veces de José Evaristo de Uriburu (1895-1898) y de José Félix Uriburu (1930-1931). Véase Arenas Luque, Genealogía de los Uriburu.

${ }^{14}$ Mateo Magariños, Diálogos con Raúl Prebisch, México, FCE, 1991, p. 29.

${ }^{15}$ Ibid., p. 33.
} 
Esa incursión en actividades culturales no es extraña en la medida en que las posiciones de profesores y catedráticos, así como las carreras públicas y eclesiásticas (Matías Linares y Sancetenea, hermano de Segundo y tío abuelo de Raúl, fue obispo de Salta y de Buenos Aires) estaban reservadas a los grupos dominantes o a los extranjeros venidos de Europa exclusivamente para su ejercicio.

Versado en alemán, inglés y castellano, y con conocimientos de francés y holandés, Albin Prebisch también se desempeñó en las lides culturales como profesor de inglés en el Colegio Nacional de Tucumán y fue propietario de la "Imprenta Albin Prebisch", que ocuparía un espacio importante en la vida cultural tucumana al dedicarse a la impresión y edición de los libros de la recién creada Universidad Nacional de Tucumán (UNT).

Sus hijos (cuatro mujeres y cuatro varones; Raúl era el cuarto varón y el sexto hijo) y nietos consolidaron la presencia de los Prebisch en el campo cultural y en los círculos intelectuales del norte argentino, de Buenos Aires e incluso en el espacio internacional. Según el genealogista Justino Terán:

Si bien de pocas generaciones en el país, (Prebisch) es un apellido que aportó figuras destacadas a su quehacer político, cultural, arquitectónico y económico. Si debiésemos identificar características sobresalientes de muchos integrantes de esta familia, señalaríamos la importancia que le dieron a los estudios universitarios y el destacarse dentro de las distintas Universidades que los tuvieron como protagonistas, ya sea en sus cuadros directivos, docentes o estudiantiles. ${ }^{16}$

La primogénita, Amalia Prebisch (1889-1979), fue ensayista, poetiza, conferencista de la "generación del centenario" 17 y publicó con frecuencia en revistas y periódicos locales. Con "dotes de docente y literata", ${ }^{18}$ enseñó en las cátedras de Literatura Argentina, Española y Clásica de la Escuela Vocacional Sarmiento y fue profesora de Metodología de la Literatura en la Facultad de Filosofía y Letras de la UNT. Adolfo Piossek, su esposo, fue rector de la UNT entre 1940 y 1942 y profesor emérito de la Facultad de Ingeniería y Derecho. Sus hijas Lucía Prebisch y Teresa Prebisch también harían carrera en la UNT.

Ingeniero y licenciado por la UBA, Ernesto Prebisch fue profesor y decano de la Facultad de Ciencias Exactas y Tecnológicas de la UNT. Julio Prebisch fue rector de esa Universidad en dos oportunidades (1929-1933 y 1938-1940) y fue identificado por los reformistas de 1918 como su modernizador por la fundación de un conjunto de nuevas facultades e institutos científicos.

El arquitecto Alberto Prebisch, también egresado de la UBA, después de una temporada en París entre 1921 y 1923 se estableció en los círculos culturales porteños como crítico de arte

\footnotetext{
${ }^{16}$ Justino Terán, "Los Prebisch. 115 años. Su historia y descendencia”, 1977, disponible en <http://www.genealogiafamiliar.net/GF-datos/Archivos/Los\%20Prebisch.pdf>.

${ }^{17} \mathrm{La}$ "generación del centenario" fue un grupo de agitadores culturales y/o estadistas (Ernesto Padilla, Juan Heller, Miguel Lillo, Ricardo Jaimes Freyre, Manuel Lizondo Borda, Ricardo Rojas, Alberto Rugués y Juan Terán) que impulsó un movimiento de revalorización cultural de Tucumán cuyo resultado es la creación de la UNT y la revitalización del estudio de la historia del norte argentino y del folklore. Véase al respecto Teresa Prebisch y Lucía Prebisch, "Introducción”, en Amalia Prebisch, La randera tucumana y otros poemas, Buenos Aires, Carcos, 1981, pp. $8-15$.

${ }^{18}$ Terán, "Los Prebisch. 115 años. Su historia y descendencia”.
} 
-en Sur, Criterio, Número, Revista de América, Vida Literaria, Martín Fierro (de la que fue director), La Nación, La Prensa, La Razón, El Mundo, El Hogar y Atlántida-, publicaciones en las que se aprecia la influencia de las enseñanzas del franco-suizo Le Corbusier en favor de la renovación de la arquitectura. Fue también profesor y decano interventor de la Facultad de Arquitectura de la UBA, miembro del directorio del Teatro Colón, presidente y vicepresidente de la Academia Nacional de Bellas Artes e intendente de la ciudad de Buenos Aires entre 1962 y 1963. En su labor arquitectónica se destacó el Obelisco de Buenos Aires (1936) y el Teatro Gran Rex (1937), que se convertirían en símbolos culturales de la ciudad.

Por su parte, el economista Raúl Prebisch se graduó en la Facultad de Ciencias Económicas de la UBA en 1922, donde fue profesor de la Cátedra de Economía Política entre 1924 y 1948. Fue el primer director de la Oficina Estadística de la Sociedad Rural Argentina, consultor técnico del ministro de Agricultura, subdirector de la Dirección Nacional de Estadística, director de la Oficina de Investigaciones Económicas del Banco Nación y subsecretario del Ministerio de Hacienda entre 1930 y 1935. También fue delegado en las negociaciones del polémico Tratado Roca-Runciman (1933), mentor del Plan de Acción Económica (1933-1935), del Plan Pinedo (1940) y de la creación del Banco Central (1935), en el que se desempeñó como gerente entre 1935 y 1943.

Si a primera vista la proyección que los Prebisch alcanzaron en el ámbito de la cultura y de los círculos intelectuales y políticos del norte argentino y de la ciudad de Buenos Aires parece improbable considerando su origen inmigrante y provincial, un examen más detallado de la historia tucumana evidencia su papel como centro de gravitación cultural y económica entre las provincias del norte. De ello es prueba la gestación de instituciones educativas y culturales y de una élite provincial culta que imprimió en las nuevas generaciones, como es el caso de los Prebisch, el "gusto por la cultura". ${ }^{19}$

\section{Aspectos de la vida económica y cultural de Tucumán en el cambio de siglo}

Con una localización estratégica en la ruta del Alto Perú, lo que posibilitó relaciones comerciales con el próspero mercado andino, el norte argentino (especialmente Tucumán y Salta) se constituyó en la época colonial como "la gran arteria mercantil del Virreinato" 20 entre los mercados boliviano, chileno y de Buenos Aires.

La crisis de la economía mercantil colonial y los nuevos límites fronterizos definidos por la República de 1816 debilitaron el vínculo entre los mercados altoperuanos y la economía agrícola norteña, que retrocedió al nivel de subsistencia. La apertura comercial promovida por las nuevas autoridades, resultado del fin de la era mercantilista, desplazó definitivamente el eje dinámico de la economía argentina del Alto Perú hacia las provincias de la pampa bonaerense (Buenos Aires, Santa Fe, Córdoba, Entre Ríos y Corrientes). En el marco del proceso de expansión del mercado mundial impulsado por la industria británica, la región pampeana creció aprovechando las oportunidades de integración que tuvieron los países de la periferia debido a la demanda internacional de productos agrícolas (lana, carne, cuero, etcétera).

\footnotetext{
${ }^{19}$ Juan Terán, La universidad y la vida, Buenos Aires, Imprenta y Casa Editorial Coni, 1921.

${ }^{20}$ Hora, Historia económica de la Argentina en el siglo XIX.
} 
A lo largo del siglo XIX se estructuraría en el país una economía de mercado de base agraria conducida por las élites liberales, que actuaron en el sentido de crear las instituciones necesarias para el desarrollo capitalista (reconocimiento del derecho de propiedad, expansión de la red ferroviaria, organización del sistema de crédito y monetario, etc.). Además, dotaron al país de un orden legal y político regido por la legislación liberal (Constitución de 1853, Código de Comercio de 1858, Código Civil de 1869, Ley de Inmigración y Colonización de 1876, Ley de Unificación Monetaria de 1881, Ley de Educación Común de 1884, etc.), fomentaron el intercambio y el consumo de bienes e integraron el mercado nacional, construyendo así las bases para el boom exportador que se produjo a fines de siglo. ${ }^{21}$

En ese período se incrementó el capital y la fuerza de trabajo, fueron removidos los obstáculos geográficos y económicos a la expansión productiva, se aceleraron los procesos de industrialización y urbanización, así como el flujo migratorio hacia las ciudades del litoral en virtud del aumento de la renta per capita, que impactó positivamente en la demanda interna de materias primas y alimentos.

También la infraestructura fue renovada con la modernización de los puertos y la construcción de la red ferroviaria, que resultó en la expansión de la frontera agrícola. Sumado a esos factores internos, el sector exportador fue impulsado por la reducción de los costos del transporte marítimo y la unificación de los mercados de capitales y de mercaderías. El resultado fue la rápida integración de la Argentina a la economía mundial a través de la conformación de "un mercado global para la producción primaria". ${ }^{22}$

La prosperidad de los mercados del litoral introdujo impulsos dinamizadores en otros sectores de la actividad económica y en regiones del interior, debido al incremento de la demanda de bienes y servicios esenciales para los sectores urbanos. El efecto multiplicador de la expansión de la economía rural exportadora pampeana fue un estímulo para que se estrecharan lazos comerciales con las demás provincias, que disponían de los factores para atender los requerimientos del tejido productivo y de las masas urbanas nucleadas en Buenos Aires y buscaban atraer para sí parte de los frutos económicos concentrados en las provincias del litoral.

Aprovechando los incentivos ligados al dinamismo exportador, Tucumán ingresó en un nuevo ciclo de desarrollo y se convirtió en el principal polo de desarrollo del norte argentino. La creación y la expansión de ingenios y plantaciones de azúcar tuvo lugar en medio de favoritismos y concesiones económicas (tarifas proteccionistas, inversiones estatales en infraestructura, facilidades para el acceso al crédito, garantía de altas tasas de ganancia, etc.) que se explican por las relaciones familiares y los acuerdos políticos entre las élites del interior y el gobierno central.

Esos beneficios estatales se remontaban al pacto firmado por la "generación de 1880", 23 que, con el fin de pacificar el interior e incentivar los negocios de familiares y amigos, ejecutó

\footnotetext{
21 "Entre 1880 y 1914, el valor de las ventas argentinas al exterior se multiplicó cerca de nueve veces. Esta expansión fue resultado del incremento de las exportaciones de productos ganaderos y, de modo aun más decisivo, del excepcional crecimiento de las ventas de granos. Para comienzos de la década de 1910, estas representaban cerca del $60 \%$ de las ventas al exterior. Para entonces, la Argentina, que exportaba más del 50\% de su producción de trigo, casi dos tercios de la cosecha de maíz y más del $80 \%$ de su lino, se había convertido en el tercer exportador mundial de granos", Hora, Historia económica de la Argentina, p. 198.

22 Ibid.

${ }^{23}$ Donna J. Guy, "La política azucarera tucumana y la generación del ochenta", Desarrollo Económico, vol. 16, n 64, enero-marzo de 1977, pp. 467-504.
} 
un programa de integración económica (transportes, comunicaciones, servicios bancarios, etc.) que dio vitalidad a la economía tucumana al garantizar a sus agentes económicos el acceso monopólico a mercados más amplios (particularmente a los centros industriales) y la integración a los puertos fluviales. ${ }^{24}$

Más allá de las iniciativas económicas, las élites nacionales que encabezaron el proyecto de organización del Estado y la nación construirían un sistema educativo oficial (instituciones escolares, agentes educadores, contenidos, dispositivos de control y punición, dirección, mecanismos de validación) con el objetivo de disciplinar e integrar a los sectores populares que, convertidos en "ciudadanos" en el contexto de un armado político-institucional democrático, debían ajustarse a nuevas obligaciones y gozar de derechos inéditos hasta entonces. ${ }^{25}$

Para sus ideólogos, especialmente Sarmiento, la "educación común" era el instrumento de combate a la barbarie y al caudillismo vigente en el mundo rural, asociado a la ignorancia, a la pobreza, a la anarquía y al fanatismo, que eran todo lo opuesto al litoral urbano y civilizado. La ignorancia de las masas y la anarquía política, "males del desierto”, debían ceder espacio a los propósitos democráticos y civilizadores que se instalarían con la instrucción primaria, base para la elevación moral de los individuos y la prosperidad nacional.

Bajo la influencia de los modelos de educación de masas de inspiración liberal e iluminista norteamericano y europeo, la escuela pública argentina fue concebida como derecho de los gobernados y obligación del Estado, que debía asegurar su carácter laico y la generalización de las primeras letras, ciencias modernas y habilidades instrumentales necesarias para la formación de cuadros técnicos. Además, contribuiría a asegurar la unidad nacional y la argentinidad a través del cultivo de su idioma y el conocimiento de la historia y de sus constructores. ${ }^{26}$ Sobre la base de esas ideas, los sucesivos gobiernos nacionales uniformaron la enseñanza, y la provisión y ampliación de la cobertura de la educación primaria, no obstante las desigualdades regionales, alcanzó resultados promisorios.

Concebidos originalmente en la presidencia de Mitre (1862-1868), los colegios nacionales se difundirían en el gobierno de Sarmiento (1868-1874). Su ministro de Instrucción Pública, el tucumano y futuro presidente Nicolás Avellaneda, explicitó en la memoria al Congreso Nacional de 1872 los motivos que debían ser el fundamento de esas nuevas instituciones:

Examínense los estudios que forman el programa de nuestros Colegios, y se verá que todos son indispensables para formar no hombres profesionales, sino hombres activos y útiles en la vida social. [...] Las miras con que se han fundado los Colegios Nacionales son indudablemente más amplias, y tienen por objeto difundir la educación en los pueblos a fin de que se formen en

\footnotetext{
${ }^{24}$ Esos favoritismos se fundaban en relaciones de reciprocidad política, en que los favores y las nominaciones eran pagados con la movilización de la máquina electoral local en beneficio del caudillo nacional: "Dado que la generación del 80 se hallaba unida por lazos familiares, y a la vez por metas patrióticas, los políticos nacionales y locales encontraron entre los parientes y amigos las adhesiones necesarias para mantener actualizadas las alianzas de 1880" (ibid., p. 508). Tal imbricación entre las élites políticas y económicas del norte argentino y los grupos dirigentes nacionales informan sobre la desenvoltura con que aquellas supieron plasmar sus intereses en la maquinaria del Estado local y nacional y obtener ventajas para sus emprendimientos". Véase Justiniano, Entramados del poder: Salta y la nación en el siglo XIX.

${ }^{25}$ Pablo Pineau, "El concepto de 'educación popular': un rastreo histórico”, Revista del Instituto de Investigaciones en Ciencias de la Educación, Facultad de Filosofía y Letras, UBA, n 13, 1998, pp. 257-278.

${ }^{26}$ Héctor Bravo, Sarmiento, pedagogo social, Buenos Aires, Editora Universitaria de Buenos Aires, 1965.
} 
todas partes hombres aptos para la producción de la riqueza, para las funciones sociales y para el ejercicio de la vida política en la República. ${ }^{27}$

Creado en 1864, el Colegio Nacional de Tucumán fue la concreción de intentos anteriores por establecer la instrucción pública en la provincia sobre bases más sistemáticas y modernas. Su proyecto se remonta a 1854, cuando la élite política local contrató a los franceses Edmundo Buessard y Filisberto Pelissot para establecer una escuela comercial y literaria. Pero de la organización efectiva se encargaría Amadeo Jacques, doctor en Letras y licenciado en Ciencias en la Universidad de París, exprofesor de la Escuela Normal francesa y del Colegio Luis el Grande. Jacques reorganiza el Colegio, reforma su proyecto pedagógico, funda el departamento de Letras y Humanidades, dirige la Biblioteca Pública instalada en el Colegio y luego asume la dirección del Colegio Nacional de Buenos Aires. ${ }^{28}$

El propósito del proyecto que representaba el Colegio Nacional de Tucumán y su impacto en la vida local se reflejan en la diversidad de áreas y competencias representadas en sus cátedras, que incluían la enseñanza de lenguas (latín, español, francés, inglés, alemán), derecho (natural, canónico, civil y constitucional), música, ciencias exactas (matemática, física, química), dibujo lineal, economía política y agronomía.

Las pretensiones modernizadoras del Colegio se evidencian en el cuerpo de profesores reclutados en Europa. ${ }^{29}$ Entre ellos, Paul Groussac, que se destacó por sus funciones como periodista, escritor y crítico literario, y fue enviado a Tucumán en 1871 por Avellaneda como profesor de matemática del Colegio Nacional. ${ }^{30}$ Tres años después fue nombrado presidente de la Comisión de Bibliotecas Populares de Tucumán (institución federal creada durante la gestión de Sarmiento para garantizar el funcionamiento de las bibliotecas) y, en los años siguientes, jefe inspector del Consejo de Inspección Pública, órgano responsable de proponer cambios en los métodos educativos, perfeccionar los cuadros docentes y fiscalizar las escuelas estatales.

Groussac coordinó los esfuerzos de modernización de los métodos de enseñanza, el mejoramiento de los edificios escolares y de su mobiliario, la compra de libros y la actualización del cuerpo docente a través de la contratación de profesores europeos que, con el fin de contrarrestar la falta de preparación y las deficiencias de los profesores nativos, debían introducir los procesos pedagógicos modernos, las nuevas técnicas de evaluación y los contenidos científicos, literarios y tecnológicos. El intelectual francés dirigió en los años 1870 el diario tucumano La Razón y, poco después de ser nombrado, en 1878, director y profesor de la Escuela Normal para sustituir al norteamericano Jorge W. Stearns, se mudó a Buenos Aires, tras su designación como Inspector Nacional de Educación. ${ }^{31}$

\footnotetext{
${ }^{27}$ Rodolfo Ceviño, Del Colegio San Miguel al Colegio Nacional: dos etapas de cultura en Tucumán, Tucumán, Editorial de la UNT, 1964.

${ }^{28}$ Manuel Lizondo Borda, Breve historia de Tucumán: del siglo XVI al siglo XX, Tucumán, Editorial de la UNT, 1965.

${ }^{29}$ Sobre los profesores extranjeros contratados (italianos, franceses, ingleses, alemanes, entre otras nacionalidades) véase Estela Barbieri de Santamarina (comp.), Inmigración en la Argentina, Tucumán, Editorial de la UNT, 1979.

${ }^{30} \mathrm{El}$ primer encuentro entre Avellaneda y Groussac es un ejemplo del proyecto cultural renovador con el que se identificara en aquellos años la clase política. Deseando regresar a Francia, el "pobre muchacho extranjero" fue convencido por el ministro de establecerse en Tucumán. A partir de entonces, la suerte del literato se vincularía a la de Avellaneda (elegido presidente de la Argentina en 1874) y al avellanedismo. Véase Paul Groussac, Los que pasaban, Buenos Aires, Taurus, 2001.

${ }^{31}$ El descontento de Groussac y, años antes, de Jacques con el medio tucumano evidencia los conflictos entre los límites del proceso de modernización cultural en una provincia del interior y las altas expectativas culturales de los intelectuales extranjeros con propósitos reformadores.
} 
Fundada en 1875, la Escuela Normal complementó los esfuerzos de modernización educacional al "hacer visibles cuestiones vinculadas con el mundo educativo". ${ }^{32}$ Considerada "un acontecimiento" 33 en la vida cultural tucumana, estaría destinada a preparar a los profesores en los nuevos métodos pedagógicos e influir sobre la enseñanza primaria. Sus diplomados actuarían como agentes de modernización de las prácticas escolares en los establecimientos educativos, que se multiplicaban gracias a las demandas de nuevos sectores sociales (la Escuela Sarmiento, por ejemplo, surgió en 1870 como primer colegio para mujeres de la provincia).

Además del impacto que representó la profusión de instituciones escolares, la vida cultural tucumana fue dinamizada por la creación de "bibliotecas populares" que, difundidas nacionalmente por Sarmiento en los años 1870, facilitaron la circulación y el acceso al libro para una población alfabetizada y una élite letrada que demandaban bienes y servicios culturales con los cuales podrían satisfacer sus emergentes aspiraciones literarias y científicas.

En ese contexto, se difundieron entidades y asociaciones que conformarían "un ambiente de sociabilidad de índole cultural en la ciudad de Tucumán", ${ }^{34}$ del que son prueba la Sociedad Sarmiento, la Biblioteca Alberdi, "asociaciones patrióticas de la juventud" (resultado de los esfuerzos escolares por alentar la historia nacional y homenajear a sus figuras públicas), clubes de lectura, veladas literarias y musicales, asociaciones culturales de diverso tipo y bibliotecas populares.

Creada en 1882 por profesores y por la autodenominada "juventud estudiosa" de la Escuela Normal y del Colegio Nacional, lo que muestra el carácter de multiplicadores culturales de esas instituciones, la Sociedad Sarmiento se transformó en el centro de la vida cultural tucumana y del norte argentino entre las décadas finales del siglo XIX e inicios del siglo XX. Nacida al calor de las reformas liberales y modernizadoras encabezadas por el Estado, que había suscitado una "cultura política abierta", ${ }^{35}$ fue la expresión de sectores medios unificados por las nuevas competencias adquiridas y por las posibilidades de ascenso abiertas por el acceso a la instrucción. Años antes, las aspiraciones de esos grupos letrados habían tenido resonancia con la creación de la efímera Facultad de Jurisprudencia y Ciencias Políticas (18751882). Pero le correspondió a la Sociedad -en ese punto como en otros anticipa al proyecto de la UNT- organizar, ritualizar (normas de ingreso y funcionamiento) y crear los espacios de preparación intelectual y los canales de expresión de las aspiraciones literarias de los jóvenes tucumanos, otorgándoles efectividad y reconocimiento público y político.

Reuniendo apoyos y recursos entre empresarios del azúcar y políticos, se creó la Biblioteca de la Sociedad Sarmiento (en poco tiempo la más importante de la región), el semanario El Porvenir y la revista Tucumán Literario (origen del periodismo cultural tucumano), el Archivo de Documentos Antiguos, el Instituto de Bacteriología e Higiene, el Museo de Historia Americana, el Museo de Historia Natural y la Academia de Bellas Artes, órganos que luego fueron incorporados (junto a la Escuela de Comercio y a la Estación Experimental Agrícola) a la UNT.

\footnotetext{
${ }^{32}$ Marcela Vignoli, Sociabilidad y cultura política. La Sociedad Sarmiento de Tucumán, 1880-1914, Rosario, Prohistoria, 2015.

${ }^{33}$ Carlos Páez de la Torre, Historia de Tucumán, Buenos Aires, Plus Ultra, 1987.

${ }^{34}$ Vignoli, Sociabilidad y cultura política. La Sociedad Sarmiento de Tucumán.

35 Ibid.
} 
Se organizaron también una serie de conferencias públicas (sobre temáticas relativas a las ciencias físicas y sociales, moral, literatura e industria) que contaron con la presencia de intelectuales de prestigio regional y nacional, una escuela nocturna para obreros, "cursos libres" con "carácter de universidad popular" ${ }^{36}$ y concursos sobre temas científicos, literarios e históricos con el objeto de promover el estudio y la investigación.

Epicentro de "un ambiente intelectual estimulante", ${ }^{37}$ el saldo alcanzado por la Sociedad Sarmiento en términos de preparación de una nueva generación letrada, promoción de iniciativas culturales, acumulación de prestigio y un bagaje de relaciones, permitió a sus miembros lanzarse, además de a la carrera política, a otros proyectos, tales como la Revista de Letras y Ciencias Sociales (RLCS) (1904-1907) y la UNT (1914), creación culminante de una generación y producto de la reciente acumulación cultural.

Espacio de sociabilidad e intercambio cultural, la Revista de Letras y Ciencias Sociales -junto con las instituciones, los proyectos y los órganos antes presentados- está en la raíz de la emergencia y el desarrollo del campo intelectual y cultural tucumano. ${ }^{38}$ Concebida por Ricardo Jaimes Freyre, Juan Terán y Julio López Mañán, profesores del Colegio Nacional y de la Escuela Normal, integrantes de la Sociedad Sarmiento y vinculados a la élite económica y política tucumana, la revista se destacó como vehículo de difusión y traducción local de las nuevas ideas, estéticas y doctrinas que circulaban en los centros culturales cosmopolitas (extranjeros y porteños). En esa dirección, propició el diálogo con escritores e intelectuales de América Latina y Europa y apoyó la carrera de jóvenes (en su mayoría tucumanos) que desempeñaron un "papel axial" 39 en el desarrollo cultural de Tucumán. La "cofradía"40 reunida en la RLCS (Jaimes Freyre, López Mañán, Terán, José I. Aráoz, Alberto Roges, Miguel Lillo, Juan Heller, Germán G. Hamilton, Abraham Maciel y Ubaldo Benci) se remonta a los espacios de sociabilidad -en buena medida familiares- y a la formación intelectual creados en la segunda mitad del siglo XIX y sedimentados a lo largo de la primera mitad del siglo siguiente.

En ese sentido, el Colegio Nacional, la Escuela Normal, la Sociedad Sarmiento y la RLCS se constituirían como espacios de encuentro entre intelectuales y escritores provinciales y extranjeros en que se forjaron lazos de amistad y proyectos culturales centrales para la organización institucional de una cultura de élite letrada tucumana con acento regional.

Su punto más alto fue la UNT, institución que idearon y pusieron en marcha, como miembros de su consejo superior, rectores, vicerrectores y profesores. Fue estructurada a partir de los "factores de cultura" ${ }^{41}$ preexistentes, tales como la Sociedad Sarmiento, el Archivo de Documentos Antiguos, el Instituto de Bacteriología e Higiene, el Museo de Historia Americana y Natural y la Academia de Bellas Artes.

De carácter experimental y práctico, la UNT auguraba mayor vinculación con la realidad y con las necesidades económicas de la provincia y de los alrededores, lo que explica la opción

\footnotetext{
${ }^{36}$ Vignoli, Sociabilidad y cultura política.

${ }^{37}$ Terán, La universidad y la vida.

${ }^{38}$ Véase Soledad Zuccardi, En busca de un campo cultural propio: literatura, vida intelectual y revistas culturales en Tucumán (1904-1944), Buenos Aires, Corregidor, 2012.

${ }^{39}$ Ibid.

${ }^{40}$ Ibid.

${ }^{41}$ Terán, La universidad y la vida.
} 
por las carreras técnicas y el énfasis en las especificidades regionales. Sus actividades debían vincularse a los fines pragmáticos de la vida productiva (mejoramientos agrícolas) y a la realización de reformas sociales (políticas agraria, sanitaria, escolar, etc.) con el objetivo de generalizar las conquistas civilizatorias posibilitadas por el avance técnico, metas y compromisos que definirían la actuación de las instituciones anteriormente creadas.

Dados tales antecedentes, que apuntan hacia un proceso de decantación y adquisición de "conciencia cultural", ${ }^{42}$ el proyecto de la nueva universidad fue la expresión máxima del progreso intelectual y del afán modernizador de los sectores letrados tucumanos. Fue también producto de la "retórica regionalista" como unidad histórica y comunidad de intereses diferenciados que, concebida y movilizada para atender a los intereses del azúcar, sirvió al propósito de construir un imaginario del "norte" como centro cultural -además de económico- en que le cabría un papel central a Tucumán. ${ }^{43}$

$$
* * *
$$

La organización institucional de la vida cultural tucumana se conectó estrechamente con el proceso de modernización socioeconómica por el que atravesó la provincia a fines del siglo XIX e inicios del XX, en la estela del boom exportador argentino. La expansión productiva propiciada por la acumulación de habilidades empresariales y técnicas agrícolas, la incorporación de moderna tecnología europea en la industrialización de la caña y la llegada de la vía férrea -“disparador" de la movilidad de capitales y hombres- ${ }^{44}$ desataron el desarrollo capitalista tucumano.

Sus efectos sobre la sociedad local se hicieron sentir a través de la progresiva complejización del espacio urbano, la diversificación del sector de servicios y el surgimiento de una clase media que, a pesar de la dependencia de los flujos de renta generados por la empresa azucarera, logró establecer un estilo de vida y demandas de nuevo tipo.

También la clase terrateniente se vio encantada con las posibilidades de la vida urbana, que le permitiría disfrutar de operetas, conciertos y conferencias (entre otras, las del poeta Leopoldo Lugones, el estadista francés Georges Clemenceau, que elogió los establecimientos educacionales de la provincia, "que no tenían nada que envidiar a los europeos") ${ }^{45}$ en los teatros Belgrano (1873), Odeón (1912) y Alberdi (1912). También le permitía regocijarse con la medalla de oro otorgada al escultor tucumano Julio Oliva en la $79^{a}$ Exposición Internacional de Roma (1909), enorgullecerse de los monumentos erigidos por artistas europeos a las "efemérides" patrias y tucumanas (la escultura en homenaje a Alberdi, por ejemplo) y entusiasmarse con el ambiente cultural generado por la conmemoración del centenario de la declaración de la independencia en 1916.

\footnotetext{
42 Ibid.

${ }^{43}$ Véase Daniel Campi y María Celia Bravo, "Aproximación a la historia de Tucumán en el siglo xx: una propuesta de interpretación”, en Fabiola Orquera (comp.), Ese ardiente jardín de la república. Formación y desarticulación de un “campo cultural”: Tucumán, 1880-1975, Córdoba, Alción, 2010, pp. 13-44.

${ }^{44}$ Ibid.

${ }^{45}$ Clemenceau se refería a Tucumán como “[...] una metrópolis esplendorosa y triunfante por la magnificencia de su fuerza y su vasta cultura”. Véase Elena Garmendia, Tucumán en los dos centenarios 1910-1916, Tucumán, Centro Cultural Alberto Rougés y Fundación Miguel Lillo, 1999.
} 
Sede del "Congreso de Tucumán”, en que se firmó en 1816 la declaración de la independencia de la Argentina, la capital de la provincia se convirtió en símbolo patrio y local tradicional de concentración de los festejos nacionales. En la celebración del centenario se mezclaron la euforia despertada por el progreso económico y social argentino de ese período y el "clima de ideas" ${ }^{" 46}$ que se consolidó en la región en torno de una identidad cultural e histórica propia.

Bajo el liderazgo del gobernador Ernesto Padilla (1913-1917), "el político de la cultura" ${ }^{47}$ más tarde ministro de Justicia e Instrucción Pública del presidente Uriburu (19301932), la UNT entró en actividad y fueron creados el Museo de Bellas Artes, el Museo de Etnografía y Ciencias Sociales, el Museo de la Industria Azucarera, el Archivo Histórico y la Casa Colonial.

También se realizaron reuniones y congresos científicos, entre los cuales se destacan la "I Reunión Nacional de la Sociedad de Ciencias Sociales" y el "Congreso Americano de Ciencias Sociales". En ese último evento, el grupo ligado a Juan Terán lanzó las bases de la "nueva escuela histórica", movimiento historiográfico que pretendió reescribir la historia argentina a través del empleo del método científico. Fueron editados, además, una serie de volúmenes que contribuyeron a la constitución del imaginario que confería a Tucumán un lugar destacado en la vida argentina. ${ }^{48}$

Los Prebisch nacieron y se criaron en la capital tucumana entre las décadas de 1890 y 1910, precisamente cuando la provincia desarrollaba más su economía, se proyectaba políticamente en las arenas decisorias y legislativas nacionales en la estela de los canales abiertos por la "generación de $1880 " 49$ y, especialmente, por el roquismo. ${ }^{50} \mathrm{Al}$ mismo tiempo, se dinamizaba su vida intelectual al crear un conjunto de instituciones educativas y culturales, productos y productoras de una élite letrada.

En esos establecimientos, espacios educativos y de sociabilidad literaria y circulación amplia de ideas y saberes, se educaron y actuaron los Prebisch. Amalia Prebisch se formó como profesora y enseñó literatura en la Escuela Normal, en la Escuela Sarmiento y en la UNT, donde también estudiaría su hermana, la arquitecta Rosa Prebisch y sus hijas, Lucía y Teresa Prebisch, respectivamente como profesoras de filosofía y de literatura. El esposo de Amalia, Adolfo Piossek, enseñó y fue rector de la UNT. Los hermanos Julio, Ernesto y Alberto se formaron como bachilleres en el Colegio Nacional de Tucumán y los dos primeros se dedicaron a la carrera docente en la UNT, de la que Julio fue dos veces rector.

Raúl Prebisch estudió en el Colegio del Sagrado Corazón, en el Colegio Nacional de Tucumán y en el Colegio Nacional de Jujuy, ${ }^{51}$ donde cursó el último año del bachillerato. A los

\footnotetext{
${ }^{46}$ Campi y Bravo, "Aproximación a la historia de Tucumán en el siglo xx: una propuesta de interpretación".

${ }^{47}$ Garmendia, Tucumán en los dos centenarios 1910-1916.

${ }^{48}$ La Nación Argentina 1810-1910; Álbum Historiográfico de Ciencias, Artes, Industrias, Comercio, Ganadería y Agricultura; Álbum Argentino (1910); La República Argentina en su primer centenario (1910), de Manuel Cosme Chueco; Tucumán a través de la historia y El Tucumán de los poetas, de Manuel Lizondo Borda; Álbum del centenario (1916); El Congreso de Tucumán (1916), de Paul Groussac, y Recuerdos Históricos (1916), de Florencio Sal. ${ }^{49}$ Guy, "La política azucarera tucumana y la generación del ochenta".

${ }^{50}$ Véase Natalio Botana, El orden conservador: la política argentina entre 1880 y 1916, Buenos Aires, Hyspamérica, 1977.

51 "Yo hice mis estudios primarios y llegué hasta el tercer año del Nacional en un colegio de padres franceses lourdistas que me enseñaron a leer y a escribir en castellano y en francés en mi provincia de Tucumán”. Cita de Prebisch tomada de Manuel Fernández López, "Raúl Prebisch y la Universidad de Buenos Aires”, en Fundación Raúl Prebisch (comp.), El pensamiento de Raúl Prebisch, Buenos Aires, Tesis, 1988, pp. 20-32.
} 
17 años, en 1918, llegó a Buenos Aires para estudiar economía en la recién creada (1913) Facultad de Ciencias Económicas de la UBA.

Su meteórica carrera en la UBA -en la que sería profesor ya en 1924, incluso antes de licenciarse como contador público- y en el sector público se explica en buena medida por su "gran cultura", ${ }^{52}$ adquirida en los tiempos de juventud en los establecimientos tucumanos y, en particular, por su versación en lengua italiana, alemán, ${ }^{53}$ francés y, sobre todo, inglés, que se estaba convirtiendo gradualmente en la lengua de la ciencia. En lo que respecta a las ciencias económicas, la supremacía del inglés era incluso más evidente, pues sus desarrollos hasta ese momento se encontraban en Gran Bretaña y en los Estados Unidos, que atraían a sus universidades y a sus órganos autónomos especializados en finanzas a los principales nombres extranjeros de ese campo de conocimiento en proceso de constitución. ${ }^{54}$

Todavía estudiante, Raúl actuó como mediador cultural al introducir Argentine international tradeunder inconvertible paper money 1880-1890, de John H. Williams, Les fondements de l'économie politique, de Adolph Wagner, Principii di economia politique, de Enrico Barone, y Principii di economia pura, de Maffeo Pantaleoni. Más tarde, ya en 1947, apoyándose en "lazos de conocimiento y reconocimiento" y en el proceso de "latinoamericanización" de la producción editorial, ${ }^{55}$ publicó en la editorial Fondo de Cultura Económica el libro Introducción a Keynes (1947), contribuyendo a difundir las ideas de ese autor en la región. El dominio precoz de esas lenguas fue una valiosa herramienta para tomar contacto con la moderna teoría económica disponible en lengua extranjera en la biblioteca de la Facultad de Ciencias Económicas. ${ }^{56}$

Tal manejo de las lenguas en que se transmitían las novedades de la teoría económica y sus nuevas virtudes le facilitó también el acceso privilegiado a datos de diferentes países y al interés que manifestó desde temprano por otras formaciones nacionales y sus semejanzas y

\footnotetext{
${ }^{52}$ Gregorio Weinberg, "Raúl Prebisch: una aventura intelectual”, en Fundación Raúl Prebisch (comp.), Prebisch y los problemas actuales de América Latina, Buenos Aires, Fundación Raúl Prebisch, 1996, pp. 53-72.

${ }^{53}$ A pesar de su origen germano, Albin se negó a enseñar alemán a sus hijos. De la misma forma que abdicara de educarlos según los preceptos protestantes en favor de los católicos, optó por socializarlos exclusivamente en la lengua nativa. Albin, como los demás inmigrantes que decidieron vincular su suerte a la del nuevo país, se empeñó en convertir a sus hijos en legítimos argentinos, respondiendo positivamente a la acción educadora del Estado que, con miras a argentinizarlos, universalizó las primeras letras y familiarizó a los recién llegados en la lengua castellana, la historia y las tradiciones culturales nacionales. En el caso específico de los Prebisch, es reveladora de ese proceso la declaración de Lucía Prebisch: "Mi abuelo Prebisch se 'argentinizó' de tal manera que no enseñó alemán a sus hijos porque quería que fueran totalmente argentinos. Era esa época en la que, como decía el escritor argentino Eduardo Mallea, la Argentina era una especie de religiosidad, los inmigrantes que llegaban se encontraban con todo un mundo por hacer, lleno de posibilidades. Mi abuelo Prebisch fue un ejemplo". Véase Mariana Smaldone, "Una tesis innovadora en la Argentina de los sesenta: fenomenología de la maternidad. Diálogo con Lucía Piossek Prebisch", Mora, vol. 19, no 1, 2013, pp. 127-135.

54 También Raúl Prebisch recibiría invitaciones para enseñar e investigar en universidades norteamericanas luego de su salida del Banco Central en 1943 y previo a su ingreso en la CEPAL en 1949. En virtud de sus prevenciones (esperaba regresar a la dirección de la banca central de su país cuando los vientos políticos cambiaran de dirección) y desencuentros de variado tipo, esa posibilidad no se concretaría. Véase Edgar Dosman, Raúl Prebisch (1901-1986): A construção da América Latina e do terceiro mundo, Río de Janeiro, Contraponto, 2011.

${ }_{55}$ Caravaca y Espeche, "América Latina como problema y como solución".

56 "En un medio ambiente académico sin hegemonías teóricas de ningún tipo en el sentido contemporáneo, Prebisch leyó de todo: de Marx a F. Turati en la tradición socialista, así como a los cooperativistas, el 'socialismo de Guildas', y asociaciones anglosajonas como G. D. H. Cole; y al J. A. Hobson leído por Lenin. Conoció también al Pareto del 'Manual' como el 'otro Pareto', el de la 'sociología'”. Cita extraída de Mallorquín, "La vuelta alrededor del mundo de Raúl Prebisch antes de 1949".
} 
diferencias con la realidad argentina. ${ }^{57}$ Además, como ocurrió con el viaje que realizó en 1923 a Australia y a Nueva Zelanda en condición de enviado del Ministerio de Hacienda de su país, ese conocimiento, sumado a su competencia específica en economía, lo volvió candidato natural para las misiones oficiales al extranjero a pesar de su corta edad. ${ }^{58}$

Además del conocimiento de varios idiomas y la formación como economista, todavía poco valorada en la jerarquía de diplomas y profesiones, Prebisch poseía una extensa red de relaciones sociales -y familiares- que resultaría decisiva para darle acceso a puestos en el Estado. La amistad con el radical Tomás Le Bretón lo convirtió en consultor técnico del Ministerio de Agricultura. Fue Luis Duhau, conservador y expresidente de la Sociedad Rural Argentina, quien lo promovió al cargo de director de la Oficina de Investigaciones Económicas del Banco Nación. Enrique Uriburu y Duhau sugirieron el nombre de Prebisch al entonces ministro de Finanzas Alberto Hueyo, quien lo nombró su subsecretario. Duhau y Federico Pinedo, respectivamente ministros de Agricultura y Finanzas del gobierno de Agustín Justo (1932-1938), promovieron a Prebisch como asesor especial y luego gerente del Banco Central. También el parentesco con el presidente José Félix Uriburu (1930-1931) y el "afecto personal" 59 entre ellos fueron decisivos para el éxito de las reformas propuestas por Prebisch, como lo demuestra la aprobación del impuesto a la renta. Según Rapoport, “[...] en esta decisión no sólo jugaron factores puramente económicos sino también lazos familiares y de $t i$ ming político". ${ }^{60}$

Por último, cabe agregar que las cualidades de Prebisch tan destacadas por sus amigos e intérpretes, tales como su capacidad de trabajo y su excepcional talento, recién se vuelven comprensibles sociológicamente al contextualizarlas en el proceso de acumulación intelectual que realizó en su provincia natal, antes incluso de su paso por Buenos Aires. Bajo la inspiración y el liderazgo de intelectuales modernizadores extranjeros, en el cambio de siglo fueron creadas un conjunto de instituciones y una élite letrada local que forjó un ambiente sensible a las nuevas influencias de conocimiento y que infundió sobre las jóvenes generaciones los valores, las ideas y los comportamientos que, conviviendo más o menos conflictivamente con las viejas prácticas y la vieja mentalidad, producirían una aguda sensibilidad y aptitud para la vida culta, conformando la vida cultural tucumana.

\footnotetext{
${ }^{57}$ Ya en el inicio de su carrera, el joven Prebisch publicará en la Revista de Ciencias Económicas textos sobre cuestiones económicas de otros países que reflejaban los intereses del grupo nucleado en torno de Alejandro Bunge: "El standard de vida en China" (1919), "La situación financiera de Francia" (1919), "La riqueza y renta del mundo antes de la guerra" (1919), "La guerra y la población de Francia" (1919), "El medio circulante y los precios en Italia" (1920), "El costo de la vida en Italia" (1920), "La Conferencia Financiera Internacional de 1920" (1921), "Ideas y comentarios. La Conferencia de Bruselas" (1921), "La Caja Internacional de Conversión. El proyecto monetario del Dr. Frers" (1923), "Determinación de la capacidad imponible. Método australiano de promedios" (1924) y "Primer informe del Dr. Raúl Prebisch sobre sus estudios financieros y estadísticos en Australia" (1924). El rutinario acompañamiento de los hechos económicos de otras realidades nacionales continuaría presente y ganaría sistematicidad en las páginas de la Revista Económica del Banco Nación, publicación creada por Prebisch en 1927 y dirigida por él hasta 1935.

${ }^{58}$ Además de los viajes que realizó a Australia y Nueva Zelanda para estudiar el régimen de distribución y tributación de la tierra, oportunidad en la que aprovechara para informarse sobre los modernos sistemas estadísticos de esos países, Prebisch viajó en 1925 a los Estados Unidos y a Canadá, encargado de preparar documentos y redactar discursos para Luis Duhau, entonces presidente de la Sociedad Rural Argentina.

${ }^{59}$ Magariños, Diálogos con Raúl Prebisch, 1991.

${ }^{60}$ Mario Rapoport, Bolchevique de salón. Vida de Félix J. Weil, el fundador argentino de la Escuela de Frankfurt, Buenos Aires, Debate, 2014, p. 325.
} 
Como mostró el artículo, las disposiciones intelectuales de Prebisch, su aptitud para la carrera científica, su liderazgo técnico y político en los escalones superiores de la máquina estatal y la confianza de que disfrutó entre la élite política de 1930 no se entienden acabadamente si no se arroja luz sobre su formación cultural de vanguardia en la próspera y cosmopolita provincia de Tucumán entre los siglos XIX y XX y el origen en la élite patricia del norte de la Argentina.

\section{Bibliografía}

Aguirre, Carlos Ibarguren, "Los antepasados: genealogía de sus respectivos linajes", 1983. Disponible en <https:// issuu.com/alfonsobeccarvarela/docs/tomo_viii >.

Arenas Luque, Fermín V., Genealogía de los Uriburu, Buenos Aires, Sociedad Impresora Americana, 1943.

Barbieri de Santamarina, Estela (comp.), Inmigración en la Argentina, Tucumán, Editorial de la UNT, 1979.

Bielschowsky, Ricardo, "Introdução", en Ricardo Bielschosky (comp.), Cinquenta anos de pensamento na Cepal, Río de Janeiro, Record, 2000, pp. 15-68.

- , Pensamento econômico brasileiro: o ciclo ideológico do desenvolvimentismo, Río de Janeiro, Contraponto, 1988.

Blanco, Alejandro, "As ciências sociais no Cone Sul e a gênese de uma elite intelectual (1940-1964)", Tempo Social, vol. 19, n 1, 2007, pp. 89-114.

Blanco, Alejandro y Brasil Jr., Antonio, “A circulação internacional de Florestan Fernandes”, Sociologia \& Antropologia, Río de Janeiro, vol .8, $\mathrm{n}^{\circ}$ 1, 2018, pp. 69-107.

Botana, Natalio, El orden conservador: la política argentina entre 1880 y 1916, Buenos Aires, Hyspamérica, 1977.

Bravo, Héctor, Sarmiento, pedagogo social, Buenos Aires, EudEBA, 1965.

Campi, Daniel y Bravo, María Celia, "Aproximación a la historia de Tucumán en el siglo xx: una propuesta de interpretación”, en Fabiola Orquera (comp.), Ese ardiente jardín de la república. Formación y desarticulación de un “campo cultural”: Tucumán, 1880-1975, Córdoba, Alción, 2010, pp. 13-44.

Caravaca, Jimena, "La Argentina keynesiana. Estado, política y expertos económicos en la década de 1930", en Mariano Plotkin y Eduardo Zimmerman (comps.), Las prácticas del Estado. Política, sociedad y élites estatales en la Argentina del siglo XX, Buenos Aires, Edhasa, 2012, pp. 36-67.

—_ ¿Liberalismo o intervencionismo? Debates sobre el rol del Estado en la economía argentina: 1870-1935, Buenos Aires, Sudamericana, 2011.

Caravaca, Jimena y Espeche, Ximena, "América Latina como problema y como solución: Robert Triffin, Daniel Cosío Villegas, Víctor Urquidi y Raúl Prebisch antes del Manifiesto Latinoamericano (1944-1946)”, Desarrollo Económico, vol. 55, nº 217, 2016, pp. 211-235.

Ceviño, Rodolfo, Del Colegio San Miguel al Colegio Nacional: dos etapas de cultura en Tucumán, Tucumán, Editorial de la UTN, 1964.

Devoto, Fernando, Historia de la inmigración en la Argentina, Buenos Aires, Sudamericana, 2009.

Dosman, Edgar, Raúl Prebisch (1901-1986): A construção da América Latina e do terceiro mundo, Río de Janeiro, Contraponto, 2011.

Fernández López, Manuel, "Raúl Prebisch y la Universidad de Buenos Aires”, en Fundación Raúl Prebisch (comp.), El pensamiento de Raúl Prebisch, Buenos Aires, Tesis, 1988, pp. 20-32.

Garmendia, Elena, Tucumán en los dos centenarios 1910-1916, Tucumán, Centro Cultural Alberto Rougés y Fundación Miguel Lillo, 1999.

Groussac, Paul, Los que pasaban, Buenos Aires, Taurus, 2001. 
Guy, Donna J., “La política azucarera tucumana y la generación del ochenta”, Desarrollo Económico, vol. 16, n 64, enero-marzo de 1977, pp. 467-504.

Hodara, Joseph, Prebisch y la Cepal: substancia, trayectoria y contexto institucional, México, El Colegio de México, 1987.

Hora, Roy, Historia económica de la Argentina en el siglo XIX, Buenos Aires, Siglo XXI, 2010.

Justiniano, MaríaFernanda, Entramados del poder: Salta y la nación en el siglo XIX, Bernal, Editorial de la UNQ, 2010.

Kay, Cristóbal, "Teorías latinoamericanas del desarrollo", Nueva Sociedad, n 113, 1991, pp. 101-113.

Lizondo Borda, Manuel, Breve historia de Tucumán: del siglo XVI al siglo XX, Tucumán, Editorial de la UNT, 1965.

Magariños, Mateo, Diálogos con Raúl Prebisch, México, FCE, 1991.

Mallorquín, Carlos, "La vuelta alrededor del mundo de Raúl Prebisch antes de 1949”, 2012. Disponible en <http:// www.centrocelsofurtado.org.br/interna.php?ID_M=847>.

Otero, Hernán, Historia de los franceses en la Argentina, Buenos Aires, Biblos, 2012.

Páez de la Torre, Carlos, Historia de Tucumán, Buenos Aires, Plus Ultra, 1987.

Pineau, Pablo, "El concepto de 'educación popular': un rastreo histórico", Revista del Instituto de Investigaciones en Ciencias de la Educación, Facultad de Filosofía y Letras, uBA, nº 13, 1998, pp. 257-278.

Pollock, David, "Raúl Prebisch: la esencia del líder”, en Edgard Dosman (comp.), Raúl Prebisch: el poder, los principios, y la ética del desarrollo, Buenos Aires, BID-INTAL, 2006, pp. 11-22.

Prebisch, Teresa y Prebisch, Lucía, "Introducción”, en Amalia Prebisch, La randera tucumana y otros poemas, Buenos Aires, Carcos, 1981, pp. 8-15.

Rapoport, Mario, Bolchevique de salón. Vida de Félix J. Weil, el fundador argentino de la Escuela de Frankfurt, Buenos Aires, Debate, 2014.

Rodriguez, Octavio, Teoria do subdesenvolvimento da Cepal, Río de Janeiro, Forense Universitária, 1981.

Smaldone, Mariana, "Una tesis innovadora en la Argentina de los sesenta: fenomenología de la maternidad. Diálogo con Lucía Piossek Prebisch", Mora, vol. 19, n 1, 2013.

Terán, Juan, La universidad y la vida, Buenos Aires, Imprenta y Casa Editorial Coni, 1921.

Terán, Justino, “Los Prebisch. 115 años. Su historia y descendencia”, 1977. Disponible en <http://www.genealogiafamiliar.net/GF-datos/Archivos/Los\%20Prebisch.pdf>.

Vignoli, Marcela, Sociabilidad y cultura política. La Sociedad Sarmiento de Tucumán, 1880-1914, Rosario, Prohistoria, 2015.

Weinberg, Gregorio, "Raúl Prebisch: una aventura intelectual”, en Fundación Raúl Prebisch (comp.), Prebisch y los problemas actuales de América Latina, Buenos Aires, Fundación Raúl Prebisch, 1996, pp. 53-72.

Zuccardi, Soledad, En busca de un campo cultural propio: literatura, vida intelectual y revistas culturales en Tucumán (1904-1944), Buenos Aires, Corregidor, 2012. 


\section{Resumen / Abstract}

\section{Raúl Prebisch y la vida cultural tucumana}

Este artículo reconstruye el milieu familiar y social del economista Raúl Prebisch e investiga la formación cultural de excelencia que recibió en la próspera y cosmopolita provincia de Tucumán, donde nació y vivió hasta los 17 años. Los datos recogidos permiten concluir que el éxito de la carrera de Prebisch entre los años 1920 y 1940 en Buenos Aires no se explica satisfactoriamente si no se tiene en cuenta la activación de su origen patricio y el amplio horizonte intelectual que adquirió en las instituciones culturales de Tucumán. Al analizar la trayectoria de Prebisch desde otro punto de partida y otra mirada, el texto contribuye a la discusión aún abierta sobre las diferentes y controvertidas fases de la vida del economista.

Palabras clave: Raúl Prebisch - Intelectuales argentinos - Desarrollo y cultura en Tucumán

\section{Raúl Prebisch and the cultural life of Tucumán}

This article investigates the family and social environment of the economist Raúl Prebisch, as well as the avant-garde cultural education he received in the prosperous and cosmopolitan province of Tucumán, where he was born, and where he lived until he was seventeen. The data collected support the conclusion that the success of Prebisch's career between the 1920s and 1940s is not satisfactorily explained without taking into account hispatrician origin and the broad intellectual horizon he acquired within the framework of the cultural institutions of Tucumán. By analyzing Prebisch's trajectory from a different starting point and another perspective, the text contributes to the still open discussion about different and controversial phases of the economist's life.

Keywords: Raúl Prebisch - Argentine intellectuals Development and culture in Tucumán

Fecha de recepción del original: 4/9/19

Fecha de aceptación del original: 6/12/19 